University of South Florida

DIGITAL COMMONS

Digital Commons @ University of

@ UNIVERSITY OF SOUTH FLORIDA

South Florida

Marine Science Faculty Publications

College of Marine Science

1995

\title{
The Source of 90-day Oscillations at Wake Island
}

Gary T. Mitchum

University of South Florida, mitchum@usf.edu

Follow this and additional works at: https://digitalcommons.usf.edu/msc_facpub

Part of the Life Sciences Commons

\section{Scholar Commons Citation}

Mitchum, Gary T., "The Source of 90-day Oscillations at Wake Island" (1995). Marine Science Faculty Publications. 2081.

https://digitalcommons.usf.edu/msc_facpub/2081

This Article is brought to you for free and open access by the College of Marine Science at Digital Commons @ University of South Florida. It has been accepted for inclusion in Marine Science Faculty Publications by an authorized administrator of Digital Commons @ University of South Florida. For more information, please contact digitalcommons@usf.edu. 


\title{
The source of 90-day oscillations at Wake Island
}

\author{
Gary T. Mitchum \\ Department of Oceanography, School of Ocean and Earth Science and Technology and Joint Institute for \\ Marine and Atmospheric Research, University of Hawaii at Manoa
}

\begin{abstract}
Energetic 90-day oscillations of sea level have been intermittently observed at Wake Island in the western tropical Pacific during the past 2 decades. The oscillations tend to occur about 1.5 years after El Niño-Southern Oscillation events, to have amplitudes of $10-15 \mathrm{~cm}$, and to persist for about 1 year. Sea surface heights from the Geosat altimeter are used to establish that these signals take the form of Rossby waves and have an energy source near the Big Island of Hawaii, which lies $40^{\circ}$ of longitude to the east. Sea level and upper layer currents from an eddy-resolving numerical model are examined and suggest that the energy source is eddies generated off the Big Island of Hawaii. These eddies appear to be associated with westward currents that intermittently impinge on the island. Several alternate hypotheses are also discussed and rejected.
\end{abstract}

\section{Introduction}

Wake Island is located in the western tropical Pacific at $19^{\circ} 17^{\prime} \mathrm{N}$ and $166^{\circ} 37^{\prime} \mathrm{E}$ (Figure 1). A tide gauge is operated at Wake by the National Ocean Service of the National Oceanographic and Atmospheric Administration, and the University of Hawaii Sea Level Center holds a sea level time series for this station from 1973 to 1992 . This sea level record is dominated at interannual frequencies by large $(10-20 \mathrm{~cm})$ drops in sea level associated with the El Niño-Southern Oscillation (ENSO) events. It has also been known for some years (K. Wyrtki, personal communication, 1985) that the sea level record at Wake Island additionally contains a strong but intermittent oscillation at a period of about 90 days. Independent of Wyrtki's observation, Mitchum and Lukas [1987], in a description of the meridional and frequency distribution of sea level variance at periods less than 100 days in the tropical Pacific, find evidence of energy at periods around 80 days in the latitude range of $12^{\circ}-25^{\circ} \mathrm{N}$. Although they hypothesize that this energy is due to eddies in the North Equatorial Current (NEC), it is likely that the 90-day oscillations at Wake Island also contribute to this spectral energy peak.

In order to focus on the 90-day oscillations, a high-pass filter (cutoff period approximately 200 days) is used to eliminate the annual and interannual variability from the daily Wake Island sea level record (Figure 2). This plot is made in such a way that the ENSO events align along the left edge of the figure and thus reveal a tendency for the 90-day oscillations to be strongest about $\mathbf{1 . 5}$ years after the ENSO events. This conclusion is supported by a complex demodulation analysis [Bloomfield, 1976] designed to estimate the temporal modulation of the amplitude of the 90-day oscillations. Time periods when this amplitude exceeds $8 \mathrm{~cm}$ are shaded on Figure 2. From this figure it is seen that the 90-day signals are particularly well developed in 1988 and are also seen in 1984. In the case of the 1988 data it is found that a fit to a pure sinusoid with a period of 90 days explains over $70 \%$

Copyright 1995 by the American Geophysical Union.

Paper number 94JC02923.

0148-0227/95/94JC-02923\$05.00 of the sea level variance. In both 1988 and 1984 the signals have an amplitude of order $10 \mathrm{~cm}$ and continue for three to four cycles. Unfortunately, gaps in the record make the conditions following the earlier ENSO events of 1972-1973 and 1976-1977 ambiguous. Note also that the 90-day signals are not seen exclusively after the ENSO events, as evidenced by strong oscillations at a similar period in 1991 .

In addition to being very energetic, the 90-day signals are interesting in that they appear to be restricted to Wake Island. A number of other sea level records (Figure 1) from the stations nearest to Wake Island were similarly examined and did not reveal such oscillations. Stations in the southern hemisphere near $20^{\circ}$ latitude were also examined and did not show any analogous 90-day signals either. On the surface this would seem to indicate that these oscillations are of small spatial scale and are probably locally forced. The small number of sea level stations in the area around Wake, however, does not allow this possibility to be accepted without further work.

The observations of these very energetic and intermittent oscillations raise a number of questions that will be addressed in this paper. For example, what is the character of these oscillations? Are they freely propagating waves or locally forced signals? In either case, what mechanism is responsible for generating such energetic oscillations? What is the spatial extent of these oscillations? Why are they not observed at other sea level stations? In the next section the sea surface height data from the Geosat altimeter, which are analyzed from November 1986 to October 1988, are used to examine the oscillations observed at Wake Island during 1988. With these data it is established that the 90-day oscillations are in fact propagating waves. I also find evidence that the waves are associated with eddies generated south of the Big Island of Hawaii (Figure 1). These eddies are discussed in more detail in the following section of the paper. In the next section, sea surface heights from a high-resolution numerical model simulation made by $\mathrm{H}$. Hurlburt at the Naval Research Laboratory (NRL) are used to study the connection between eddies south of the Big Island and waves at Wake Island in more detail. The paper concludes with a discussion of the eddy generation mecha- 


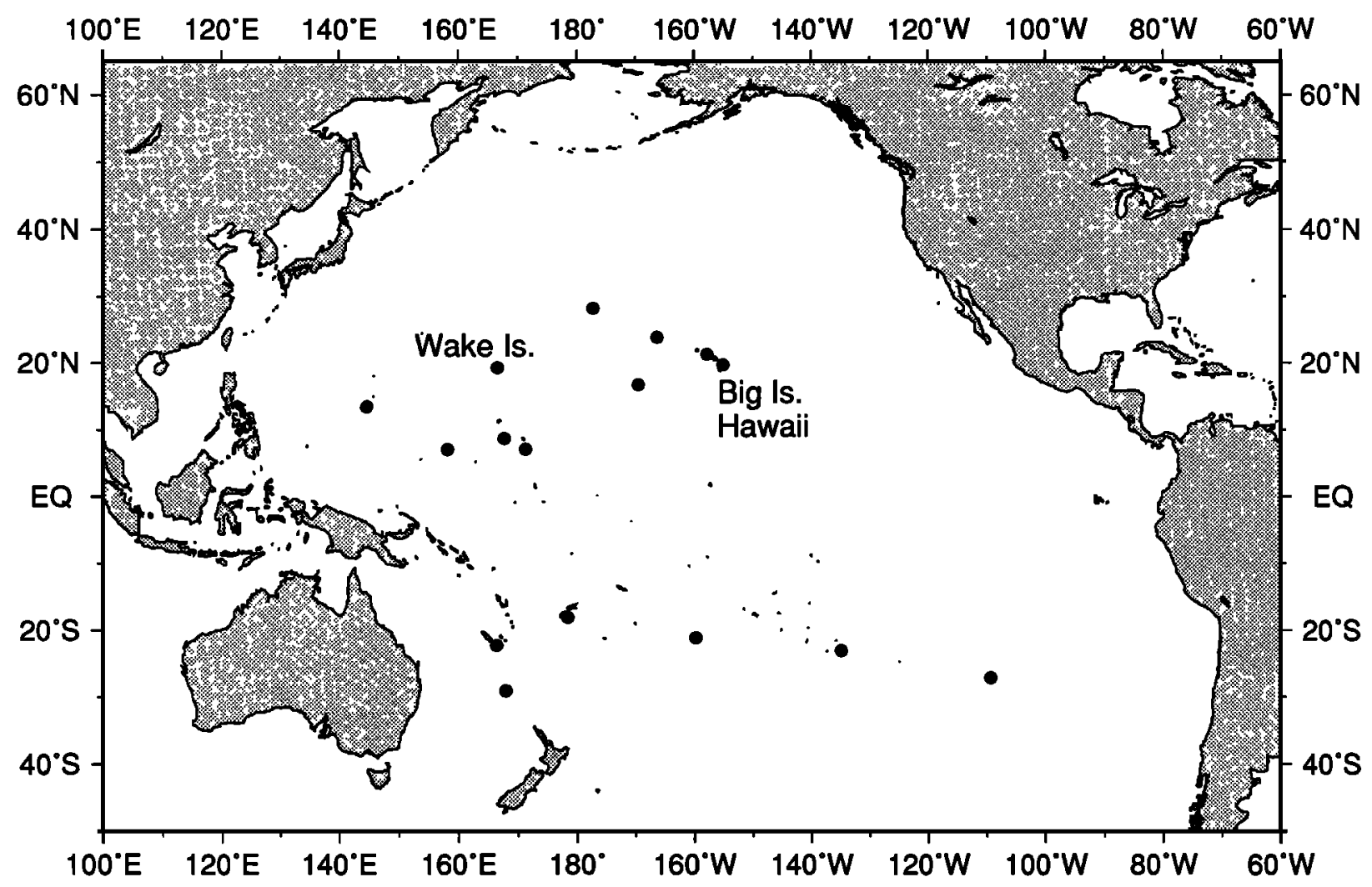

Figure 1. This map shows the location of Wake Island in the western Pacific where intermittent 90-day oscillations of sea level are observed. Also shown, at about the same latitude but $40^{\circ}$ of longitude to the east, is the Big Island of Hawaii, where active eddy generation occurs. The unlabeled solid circles represent other sea level stations with time series that were also examined for evidence of the 90 -day variations observed at Wake Island.

nism and a consideration of alternative hypotheses that would explain the observed Wake Island waves.

\section{Brief Review of Rossby Wave Theory}

Because many of the results described in the following sections will be discussed within the context of midlatitude Rossby wave theory, a brief review will be given here. All of the material presented here is given by Gill [1982, Chapter 12], and further details can be obtained there. The relevant Rossby wave theory is developed on a midlatitude $\beta$ plane, upon which the Coriolis parameter is defined as

$$
f(y)=f_{0}+\beta y
$$

where $y$ is the meridional coordinate, $f(y)$ is the Coriolis parameter, $f_{0}$ is the value of the Coriolis parameter at the latitude where the $\beta$ plane is centered, and $\beta$ is the rate of change of $f$ with $y$. In this case the dispersion relation is

$$
\omega=-\beta k /\left(k^{2}+l^{2}+L_{R}^{-2}\right)
$$

where $\omega$ is the frequency, $k$ and $l$ are the zonal and meridional wavenumbers, respectively, and $L_{R}$ is the internal Rossby radius, which is defined as

$$
L_{R}=c / f_{0}
$$

In (3), $c$ is the speed for the first baroclinic mode that arises as an eigenvalue in an expansion of the vertical structure on normal modes. In the region near $20^{\circ} \mathrm{N}$ between Wake Island and Hawaii $c$ was estimated from in situ density profiles to be $2.8 \mathrm{~m} / \mathrm{s}$, which gives a value of $56 \mathrm{~km}$ for the Rossby radius when $f_{0}$ and $\beta$ are computed at $20^{\circ} \mathrm{N}$.

It will be seen in subsequent sections that the magnitude of the wavenumber is very much less than the inverse of the Rossby radius, which allows the use of a longwave approximation. The resulting dispersion relation is

$$
\omega=-\beta k L_{R}^{2}
$$

These long Rossby waves are nondispersive and propagate both phase and energy to the west. Using $56 \mathrm{~km}$ for the Rossby radius, the zonal wave speed is approximately 7 $\mathrm{cm} / \mathrm{s}$.

For a given latitude and associated $f_{0}$ and $\beta$ values, there is a maximum frequency at which Rossby waves can exist. This maximum frequency is given by

$$
\omega_{\max }=0.5 \beta L_{R}
$$

A wave of a given frequency thus has a latitude, called the turning latitude, beyond which it becomes evanescent. For $20^{\circ} \mathrm{N}$ and a $c$ of $2.8 \mathrm{~m} / \mathrm{s}$, the maximum frequency corresponds to a minimum period of about 120 days. This is, 


\section{Wake Island high-passed sea level : 1972-1991}

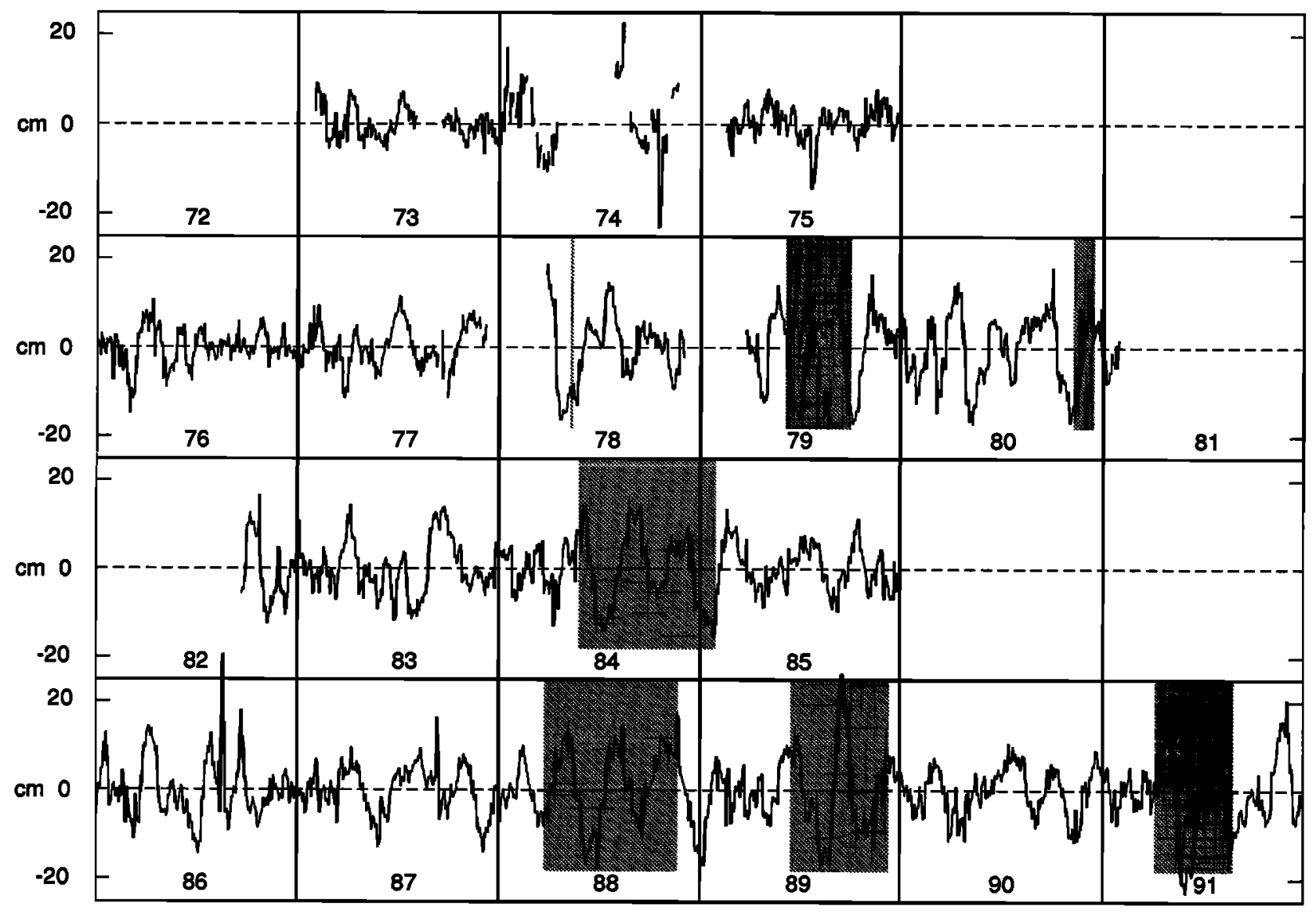

Figure 2. Daily sea level values obtained at Wake Island are high passed with a convolution-type filter having half-amplitude response at $200 \mathrm{~d}$. Each line of the plot corresponds to the time series from the onset of an ENSO event to the beginning of the next event. Vertical lines are placed at January 1 of each year. Sea level units are in centimeters. The shaded areas mark time periods where a complex demodulation analysis indicates that the amplitude of the 90-day oscillation is greater than $8 \mathrm{~cm}$.

however, the intrinsic period of the oscillations. If there are mean currents, then the observed frequency will be Doppler shifted. The observed oscillations, which have a period of 90 days and a wavelength of order $600 \mathrm{~km}$, would be associated with an intrinsic period longer than 120 days for a westward mean flow in excess of $1-2 \mathrm{~cm} / \mathrm{s}$. Although the direction and magnitude of this mean flow are reasonable for this area, the mean flow is too small to verify directly from other observations. Consequently, I can only conclude that the observed waves are near their turning latitude.

Finally, note from (3) and (4) that as the latitude and thus $f_{0}$ and $\beta$ are changed, the westward speed of the waves varies as $f_{0}^{-2}$. This dependence will be demonstrated from the observations in the next section and interpreted as evidence that the propagating signals under discussion are indeed Rossby waves. Note also that equatorial Rossby waves have discrete meridional modes and that this $f_{0}^{-2}$ dependence only applies if each mode is associated with its turning latitude. This point is discussed in more detail by Gill [1982] but will not be treated here since the midlatitude theory is used almost exclusively in this paper.

\section{Results From Analysis of Geosat Data}

Sea surface height data from the Geosat altimeter were computed from a collinear analysis covering the period from the beginning of the Exact Repeat Mission in November 1986 to October 1988, after which the data quality had degraded significantly. Geosat had a repeat period of 17 days, which means that any particular subsatellite point was only observed once every 17 days. At the latitude of Wake Island, Geosat had a track spacing of approximately $75 \mathrm{~km}$. The temporal resolution is not really adequate for studying 90-day variability, but it can be improved by making use of data from more than one track; that is, it is possible to trade spatial for temporal resolution. The Geosat data have been widely used in studies of tropical variability, and Mitchum and Kilonsky [1994] provide a recent review of tropical sea level variability as observed from altimeters, with emphasis on Geosat observations.

One part of a collinear analysis that typically varies from one researcher to another is the correction for residual orbit error. This correction is necessary because the computed 


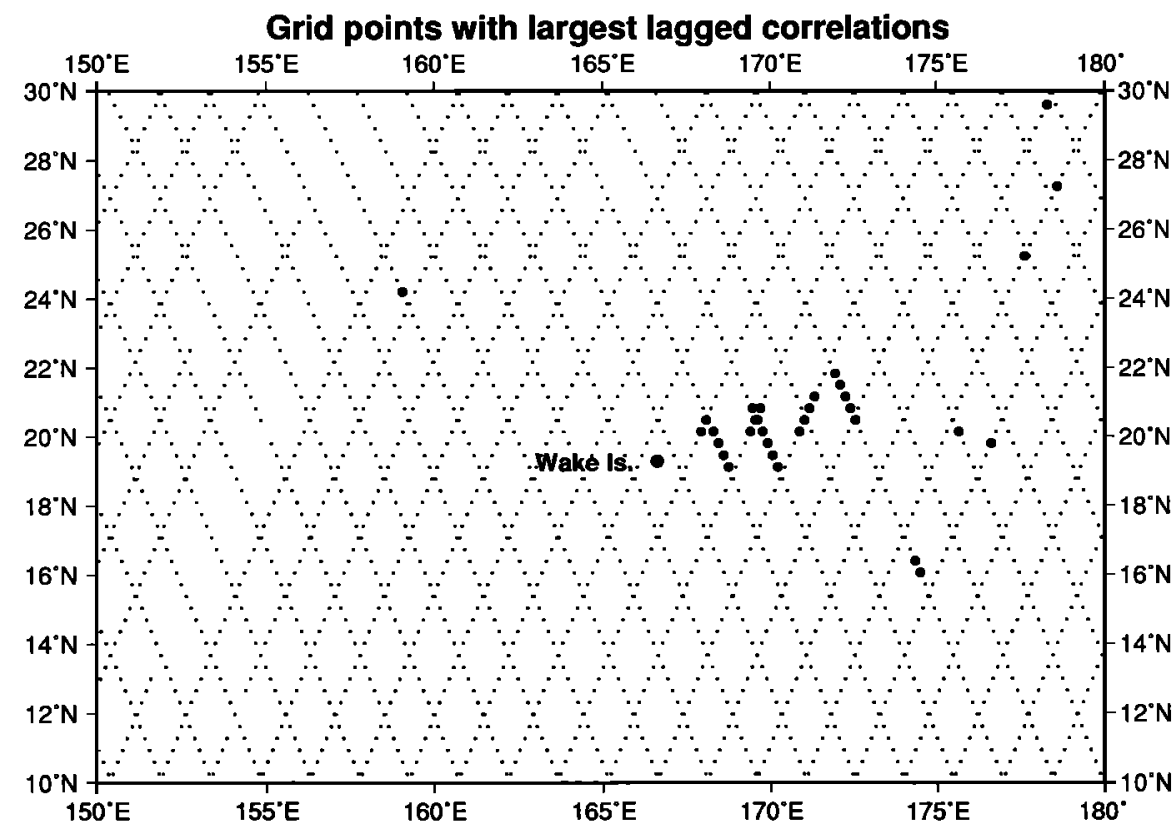

Figure 3. The dots show the locations of all of the Geosat grid points where lagged correlations versus Wake Island sea level were computed. The solid circles show grid points where significant lagged correlation values were found that were also consistent with 90 -day oscillations. The location of Wake Island is marked by the larger solid circle.

orbits, which in this case are based on the GEM-T2 gravity model [Haines et al., 1990], still have errors of order $30 \mathrm{~cm}$. Fortunately, it has been known for some time that this residual orbit error is dominated by long wavelength terms. Tai [1988] showed that this error can be modeled by a sinusoidal term with a wavelength corresponding to one cycle per revolution around the Earth. This type of correction is also applied in this work but with a few modifications. The most important difference is that I allow the amplitude and phase of the fitted sinusoid to vary in time. This is accomplished by expanding the amplitude and phase in Chebyshev polynomials and fitting the slow amplitude and phase variation over nine revolutions at a time. Chelton and Schlax [1993] have recently described a similar technique in greater detail and confirm the effectiveness of this approach in reducing the residual orbit error.

The sea surface height data from the collinear analysis are in the form of time series at a set of grid points located at approximately $36 \mathrm{~km}$ spacing along the nearly meridional satellite ground tracks. The time series at each grid point are 2 years long with a spacing of 17 days. One further calculation was done before using these data. The time series at each grid point were used to fit a model of the low-frequency variability that consists of annual and semiannual harmonics and a quadratic polynomial to estimate the interannual signal associated with the 1986-1987 ENSO event. This fitted model was then subtracted from the original data in order to approximate the high-pass filter applied to the sea level data at Wake Island, which eliminates variability at periods longer than 200 days. This approach is necessary because the Geosat time series are too short to allow the use of the same filter applied to the tide gauge data. It is this highpassed version of the Geosat data that is used in all subsequent analyses.

\subsection{Signals Near Wake Island}

Before examining the Geosat data in detail it is necessary to determine whether the Geosat sea surface heights at Wake Island reveal the 90-day signals observed at the Wake sea level gauge. The first attempt to check for these signals used a time series formed by compositing all Geosat tracks passing within $4^{\circ}$ east and west of Wake Island and simply ignoring the longitude. This $8^{\circ}$ bin width results in a time series with points separated by about 1.5 days on average, which is adequate to resolve the 90-day signals. Unfortunately, this time series has no correlation with the highpassed Wake sea level data. Of course, this could happen if the 90-day signals were due to a propagating signal that introduces time lags between the time series at different longitudes.

In order to check for propagating signals a lagged correlation analysis was done between the Wake Island sea level record during the period of active 90-day variability in 1988 and the Geosat sea surface height time series. In addition to finding the lag with maximum correlation, it was also required that there be correlation peaks at positive and negative lags that were separated by 90 days, which are expected for 90-day oscillations. This additional requirement is helpful in dealing with the inherently large noise level in the Geosat data. The significance of the lagged correlations thus identified was tested with a set of Monte Carlo simulations that model the Geosat data at any grid point as white noise. No account was made, however, of possible spatial correlations in the altimetry data.

Grid points with significant lagged correlations consistent with 90-day oscillations were almost all found immediately east of Wake Island (Figure 3). In all, 32 grid points were identified as having significant correlations, whereas the 


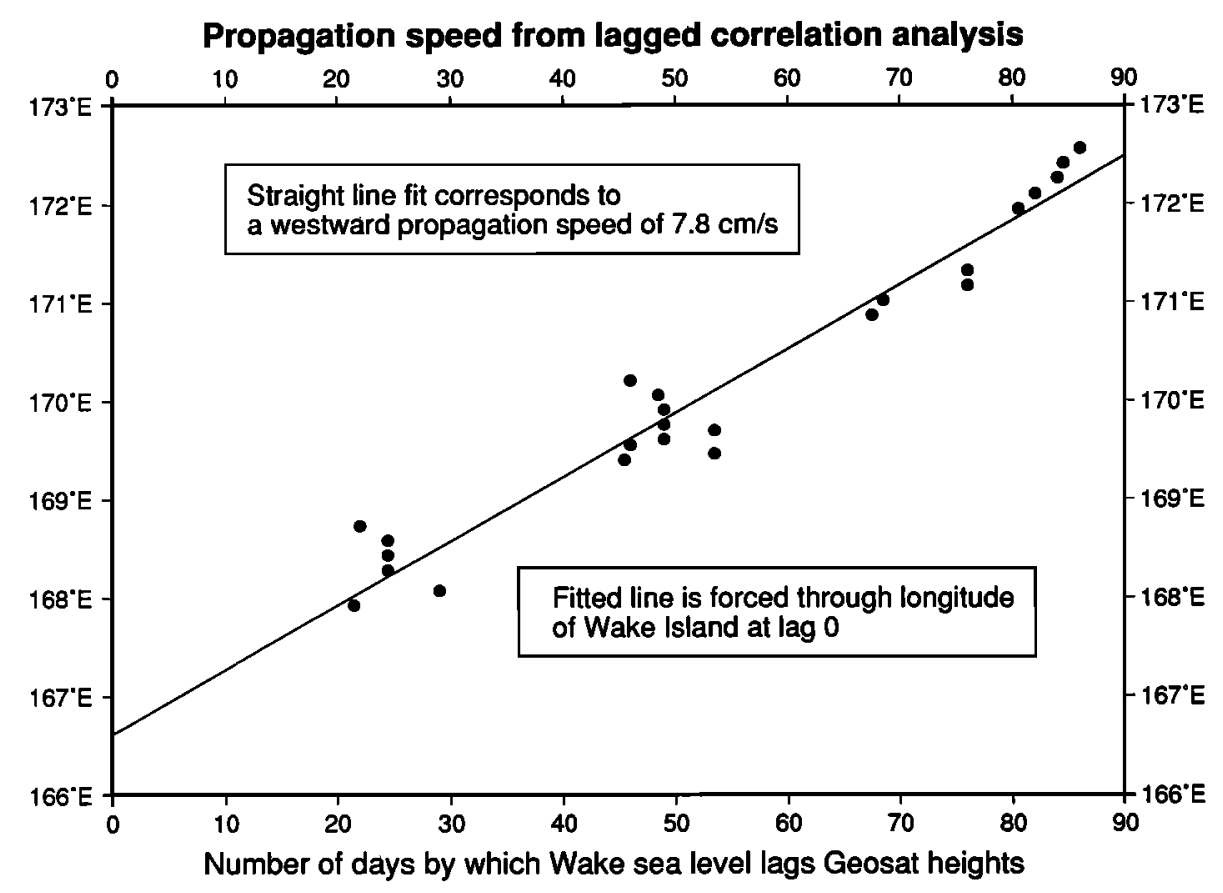

Figure 4. The solid circles show the lags at maximum correlation versus the longitudes of the grid points used in the lagged correlation analyses. Points are shown only for the grid points within $7^{\circ}$ of Wake Island that have significant correlations (see Figure 3). The straight line is from a least squares fit of a slope to the longitude versus lag curve.

simulations predict five to occur by chance. The fact that most of the points lie close to Wake is not surprising if one expects the correlation to decrease with distance. The lack of significant results west of Wake Island may be due to large numbers of missing points in the Geosat time series west of about $160^{\circ} \mathrm{E}$. If the lag corresponding to the highest correlation is plotted versus longitude (Figure 4), it is found that the 90-day signal is propagating to the west at $7.8 \mathrm{~cm} / \mathrm{s}$. Note from section 2 that this is close to the speed expected for a first baroclinic mode Rossby wave at this latitude.

Given this estimate of the propagation speed, it is possible to try again to construct a time series at Wake for comparison with the sea level record. This is done by shifting each Geosat grid point time series by a time lag computed from the estimated propagation speed and the longitude difference between Wake and each grid point. This calculation results in a Geosat time series at Wake that is very different from the nonpropagated data and also compares well with the observed sea level time series (Figure 5). The solid curves on the top and bottom lines of this figure are from a gridded time series computed as the median value of all points in 10-day intervals. The time series computed with an allowance for propagation is very similar to the Wake Island sea level record (Figure 6).

Although this result is encouraging, it may not be too surprising since the Wake sea level data were used in the lag correlation analysis to fit the propagation speed. The result was checked by using only the Geosat data, again taken in $8^{\circ}$ longitude bins, and fitting the data to zonally propagating sinusoids of the form

$$
h(t)=A \cos (\kappa x-\omega t-\phi)
$$

where $h(t)$ is the Geosat time series, $t$ is time, $x$ is zonal coordinate, and $\omega$ is the frequency corresponding to 90-day waves. $A$ and $\phi$ are the wave amplitude and phase, and $\kappa$ is a zonal wavenumber; these last three parameters are fit by least squares. This calculation in the region just east of Wake Island gives a propagation speeds of 7-8 cm/s and zonal wavelength estimates of order $600 \mathrm{~km}$.

The analyses of the Geosat data near Wake Island thus reveal two important things. First, a lagged correlation analysis shows that the observed sea level signal is associated with westward propagating signals in the Geosat data. This result is confirmed by an analysis using only Geosat data, which also yields an estimate of the length scale of the 90-day signals. Second, the propagation speed and the fitted wavenumber at a period of 90 days are close to that expected for Rossby waves at this latitude.

\subsection{Large-Scale Description of 90-Day Variability}

The lagged correlation analysis discussed above is adequate for studying the propagating features near Wake Island where it is expected that there is a useful correlation. At larger distances, however, this technique will not work well. The fit described in (6), on the other hand, does not depend on proximity to Wake Island, although it does assume the period of the oscillations. This same fitting procedure was applied to all of the Geosat grid points between $50^{\circ} \mathrm{S}$ and $50^{\circ} \mathrm{N}$ in the Pacific in order to study the large-scale distribution of energy at a period of 90 days.

Although fits were made at all grid points, only points where the fitted amplitude of the 90-day sinusoid exceeds 4 $\mathrm{cm}$ will be discussed; Figure 7 shows the estimated zonal 


\section{Effect of allowing for zonal propagation in Geosat heights}

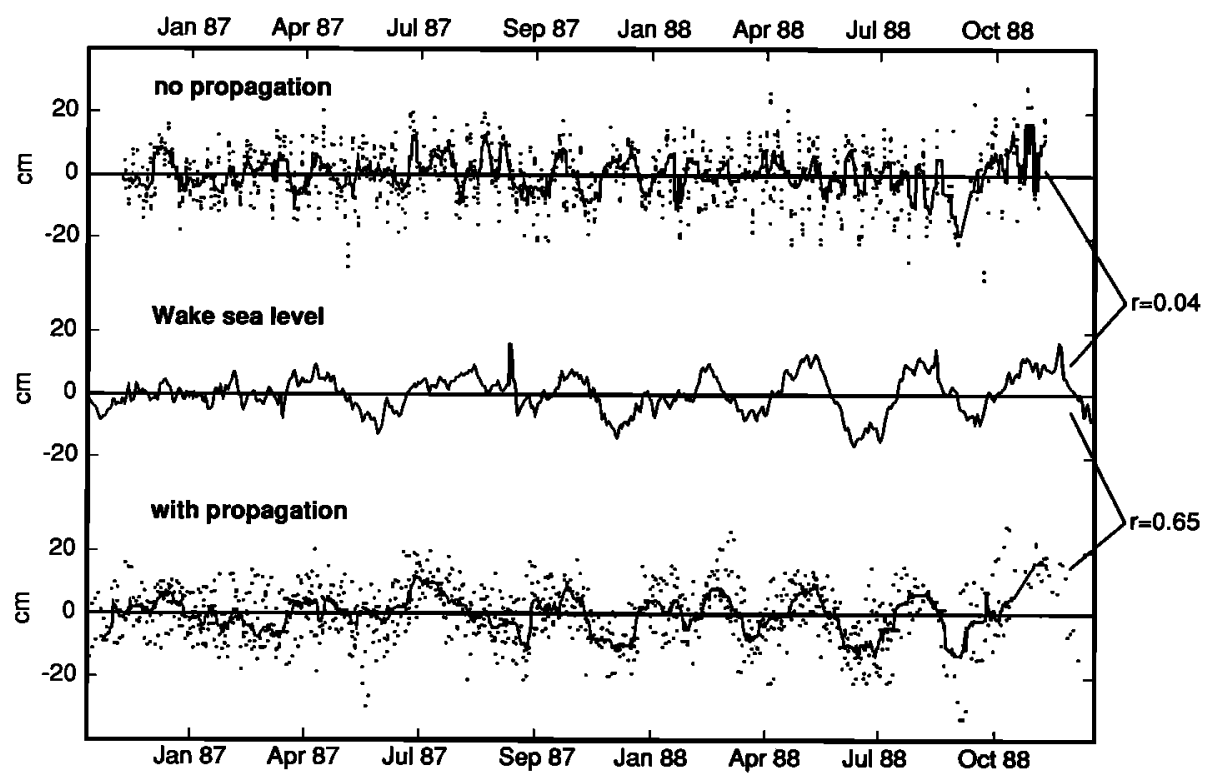

Figure 5. (top) The individual points in the curve are a composite of all Geosat grid point time series within $4^{\circ}$ longitude of Wake Island. The longitude of the individual grid points has been ignored. (middle) The curve shows sea level from Wake Island. (bottom) The individual points in the curve are from the same Geosat grid point time series but with a temporal lag introduced, which is computed from the fitted propagation speed. The correlations noted on the figure are computed between the Wake Island sea level and the gridded time series shown by the solid curves (top and bottom). These gridded series are obtained by computing the median value of all points falling in 10-day windows.

wavenumbers at only those points. Thus the appearance of a wavenumber vector on this figure also indicates where the 90-day waves are most energetic. Note first that the energy to the east of Wake Island $\left(19^{\circ} \mathrm{N}, 166^{\circ} \mathrm{E}\right)$ is confirmed. Also, the meridional distribution of the grid points with amplitudes greater than $4 \mathrm{~cm}$ shows that most of the 90-day energy is centered around a latitude of $20^{\circ}$ in both hemispheres, which is interesting in light of the observation made in the previous section that the wavenumber and propagation are consistent with Rossby waves. This is because Rossby waves at a

Wake sea level vs. "propagated" Geosat heights

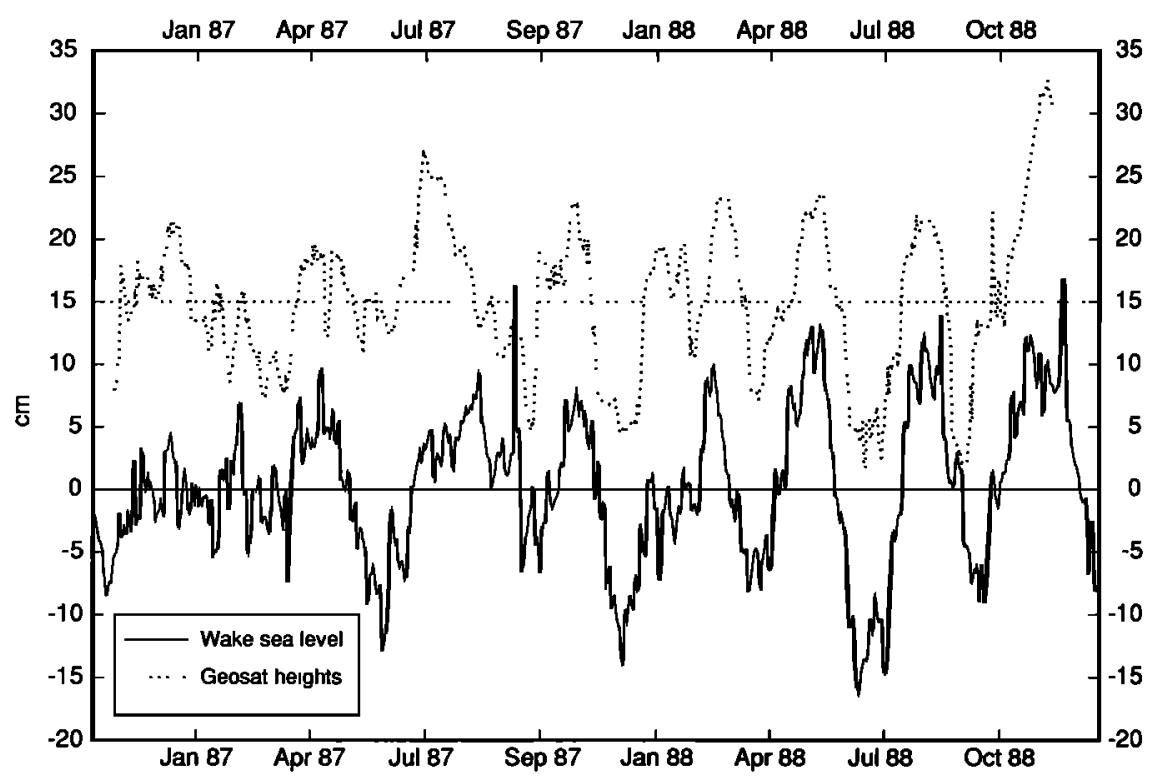

Figure 6. The solid and dotted curves on this figure are identical to the middle and bottom solid curves, respectively, in Figure 5. This figure facilitates comparison of the Wake sea level and the Geosat height data after allowance is made for propagation. The correlation between these curves is 0.65 . 


\section{Zonal wavenumbers where amplitude of 90-d signal exceeds $4 \mathrm{~cm}$}

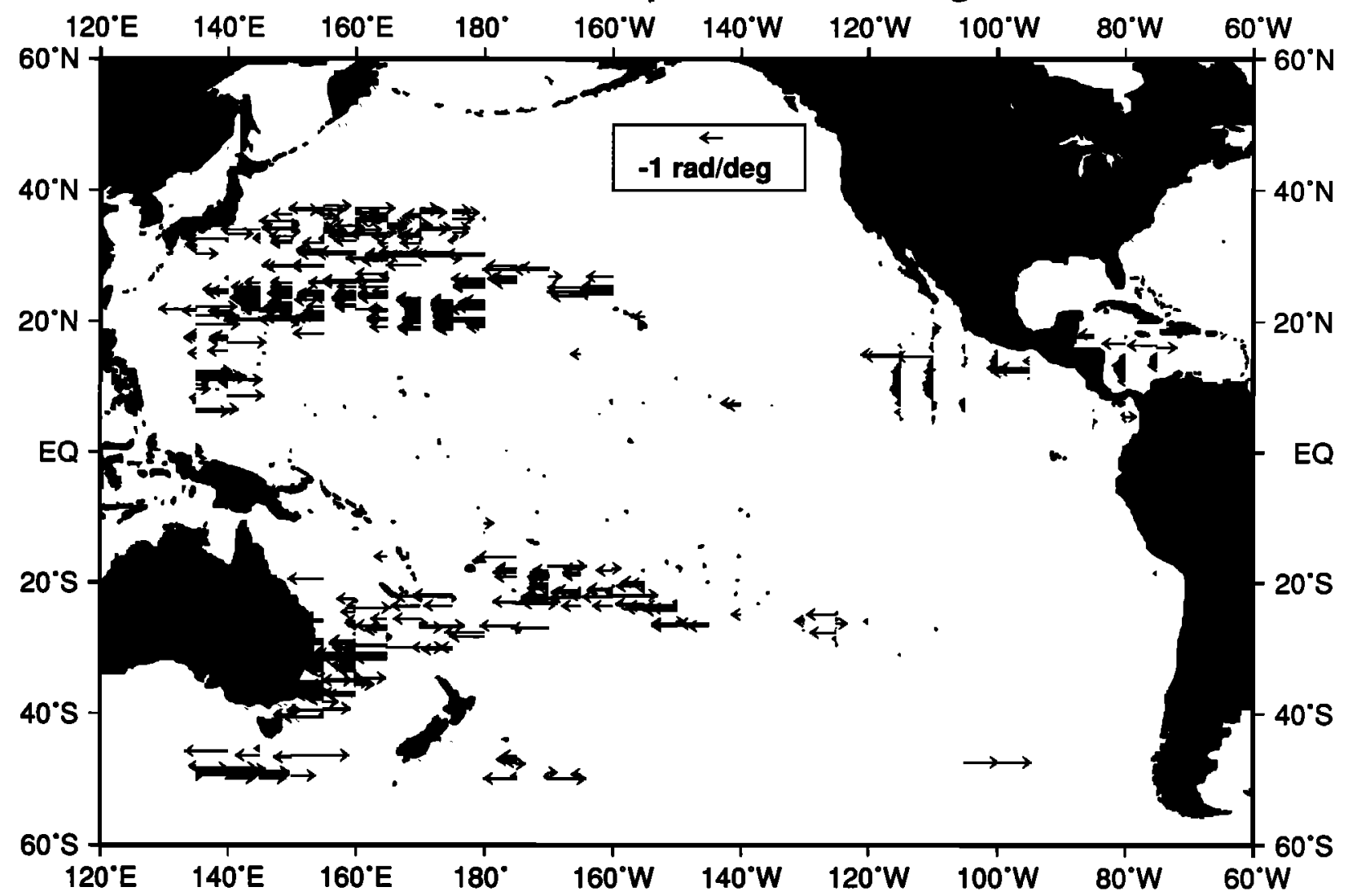

Figure 7. Fitting the Geosat grid point time series to propagating waves at a period of 90 days (see (1)) results in wavenumber estimates as well as amplitudes. Wavenumbers are plotted on this figure only where the fitted amplitude exceeds $4 \mathrm{~cm}$. The wavenumbers are plotted as vectors to show the direction of phase propagation, which is determined from the sign of the wavenumber. A scale vector is shown in the upper middle portion of the plot.

period of 90 days are expected to have their turning latitude near $20^{\circ}$ and thus should have more energy at that latitude [Gill, 1982]. This is taken as further evidence that the signals observed at Wake Island are the sea level expression of westward propagating Rossby waves.

The wavenumbers shown in Figure 7 are plotted so as to point in the direction of propagation, and the scale vector plotted in the upper middle portion of the figure corresponds to a wavelength of $600 \mathrm{~km}$, which would approximately fit the Rossby wave dispersion curve. Most of the grid points near $20^{\circ}$ do indeed take about this wavenumber. Further north in the western North Pacific the propagation is eastward; this may be consistent with waves that are Doppler shifted by the Kuroshio. The eastern Pacific region near $10^{\circ} \mathrm{N}$ has generally smaller wavenumbers (larger wavelengths), which is consistent with faster Rossby waves at lower latitudes. It is considered unlikely that these waves are connected with the phenomenon observed at Wake Island, however, since the fitted waves are of small amplitude between this region and the area of Wake.

\subsection{Tracking the Propagating Signals to Wake Island}

The analyses done thus far have either required use of the Wake Island sea level data or have assumed monochromatic wave signals. Both of these approaches have yielded results, but it is desirable to constrain the analysis as little as possible. This is preferable for tracking the signals from Wake Island to their source because those approaches may miss signals that are not well modeled by 90 -day sinusoids farther from Wake.

A more general approach to tracking the propagating signals was devised and proceeds as follows. First, at a given latitude all the grid point time series from an $8^{\circ}$ longitude bin are taken and combined with time lags computed according to a given propagation speed. The resulting time series is gridded using the same 10-day median calculation described earlier, and the variance of the resulting time series is computed. Finally, the variance of the gridded time series is maximized by varying the propagation speed that was given at the start of the calculation. In this way the propagation speed and a time series that emphasizes propagating signals are determined without any assumptions about the type of waves contained in the data; that is, no assumption is made about the speed or the period of the waves. This analysis is carried out between $10^{\circ} \mathrm{N}$ and $30^{\circ} \mathrm{N}$ from west of Wake Island $\left(160^{\circ} \mathrm{E}\right)$ to east of Hawaii $\left(120^{\circ} \mathrm{W}\right)$. The result is a set of propagation speeds as well as the time series from the fitting procedure itself.

Zonal averages of the speeds computed from this analysis are plotted versus latitude in Figure 8 . Also plotted on this 


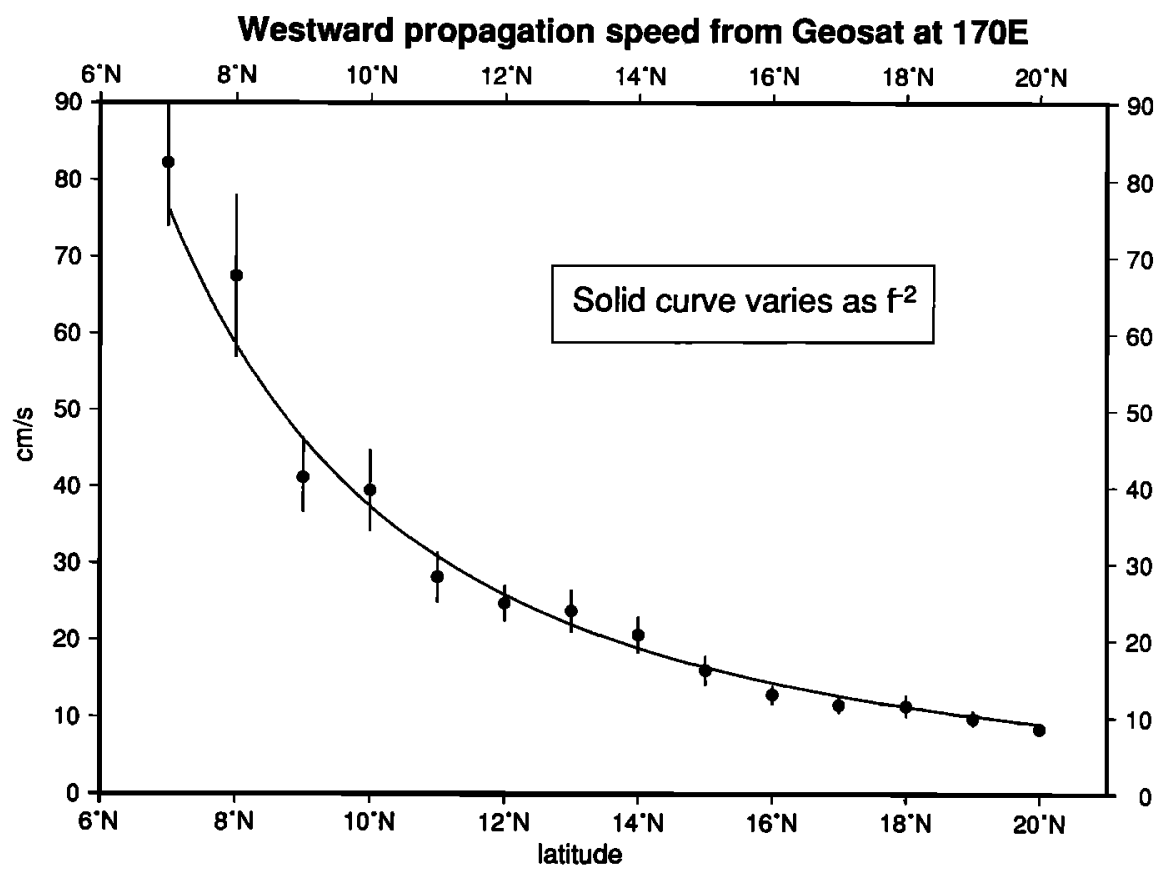

Figure 8. The solid circles represent the zonal average of the propagation speeds found from the procedure described in the text. At each latitude, there are approximately 10 independent estimates of the propagation speed. The error bars represent one standard deviation about the zonal average. The solid curve shows the meridional variation expected for Rossby waves.

figure is the $f^{-2}$ variation with latitude that is expected for Rossby waves, as discussed in section 2 . The striking agreement of the data with this theoretical curve is strong evidence that the propagating portion of the sea surface height data is dominated by Rossby wave variability. A similar result has been obtained in the vicinity of the Hawaiian Islands by van Woert and Price [1993]. It is important to note again that there is nothing in the calculation procedure that forces the propagation speeds to match the Rossby wave speeds. The variance ratio of the propagating signal as compared to the signal obtained by averaging without propagation is shown in Figure 9. The variance ratio is large along $19^{\circ} \mathrm{N}$ between the Big Island of Hawaii and Wake Island, which means that the sea surface variations in this area are dominated by propagating signals. Large values of this ratio are also found north of $25^{\circ} \mathrm{N}$, but these signals are distinct from the variability along $19^{\circ} \mathrm{N}$.

A very straightforward description of the sea surface height variability can be made by simply contouring the time-longitude variations along $19^{\circ} \mathrm{N}$ (Figure 10). First, note that a cut through this figure at $166^{\circ} \mathrm{E}$ corresponds to a time series near Wake Island and that this time series agrees well with the observed sea level variation at Wake. This time series comparison is similar to that shown in Figure 6. More importantly, it is clear from this figure that the propagating signals originate near $155^{\circ} \mathrm{W}$, which corresponds to the Big Island of Hawaii, and move westward to the longitude of Wake Island $\left(166^{\circ} \mathrm{E}\right)$ in $500-600$ days. The propagation characteristics east of Hawaii are different, and the amplitude of the variations is smaller. Between the Big Island and Wake, however, it is easy to track the propagating signals. Similar plots at other latitudes show that the 90-day signals are of very limited meridional extent. This conclusion is supported by the fact that the signals are not observed at the Johnston Island tide gauge located at $17^{\circ} \mathrm{N}$ and $170^{\circ} \mathrm{W}$.

\section{Eddies Near the Big Island of Hawaii}

The analysis in the previous section leads to the conclusion that the source of energy for the 90-day Rossby waves observed at Wake Island is at the Big Island of Hawaii. Also, from the computed propagation speed, the energy source is active about 1.5 years prior to the appearance of the waves at Wake Island. As discussed in the introduction, there is a tendency for these waves to appear 1-2 years after ENSO events, which implies that the energy source is active during the events themselves.

It is known that the region south of the Big Island of Hawaii is a source of mesoscale eddies. Patzert [1969] provides a summary of some early work concerning these eddies and an extensive compilation of the hydrographic descriptions for them. He describes a large number of cyclonic eddies that tend to be relatively small and to occur west of the Big Island. These eddies tend to stay in the lee of the island chain and are attributed to forcing by the wind field. Using his data, I have determined that there is a tendency for these eddies to be somewhat stronger during ENSO events. Specifically, two of the three largest eddies observed during 1963-1967 were associated with the ENSO event of 1965. If the eddies were generated without regard to ENSO events, there is less than a $10 \%$ chance of this happening.

Patzert [1969] also describes larger anticyclonic eddies that occur off the southern end of the Big Island. Unfortunately, these eddies tended to be outside the region surveyed, and relatively little data exist for them. These eddies 


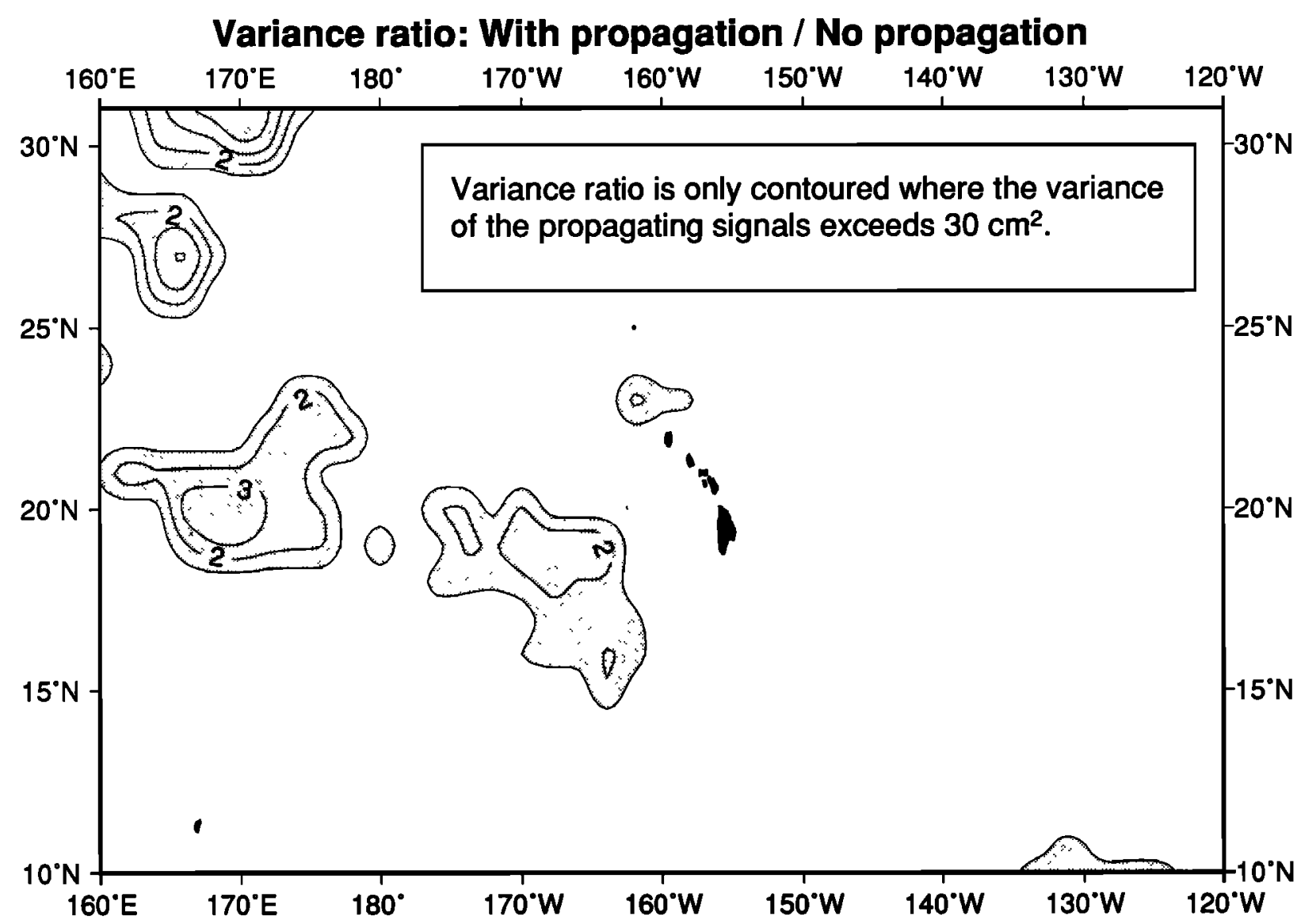

Figure 9. The variance of the Geosat time series computed with allowance for propagation is divided by the variance of the Geosat time series that results if the individual grid point time series are composited without allowing for propagation. This ratio is large where propagating signals dominate the Geosat heights, but the ratio can be misleading where there is little variance. Therefore the ratio is only contoured where the variance of the Geosat time series exceeds $30 \mathrm{~cm}^{2}$.

move away from the Big Island to the west relatively quickly, possibly because they are exposed to westward currents flowing by the Big Island. It is also possible that they are forced by such current flows, as will be discussed in the next section. Concerning the westward currents impinging on the Big Island, there is some weak evidence from the 1965 ENSO event that these currents are stronger during the events [Seckel, 1975]. If the eddies are indeed separated by the flow or generated by it, then such a westward acceleration during ENSO events would help to explain the interannual modulation of the 90-day sea level signals observed at Wake Island. Relatively little information on the currents is available, however.

An interesting case is also found in the Hansen World Ocean Circulation Experiment (WOCE) drifter data set (Figure 11). Drifter 6873 steadily approached the Big Island from the east at $10-15 \mathrm{~cm} / \mathrm{s}$ and upon passing the south point of the Big Island in late August 1989, became entrained in an anticyclonic eddy with a diameter of order $100 \mathrm{~km}$. The eddy then propagated away to the west at approximately $6 \mathrm{~cm} / \mathrm{s}$. Of course, this event did not occur during an ENSO event, but it is interesting that about $\mathbf{1 . 5}$ years later at Wake Island there were 90-day oscillations (Figure 2) that did not fit the ENSO timing.

\section{Comparison With Sea Surface Heights From NRL Model}

In order to further evaluate the generation of eddies by current flows near the Big Island of Hawaii, sea surface heights and upper layer currents from a high-resolution, eddy-resolving numerical model simulation were examined. The model output was provided by $\mathrm{H}$. Hurlburt of NRL and is from a six-layer model with $1 / 8^{\circ}$ horizontal resolution. The simulation is driven by monthly mean winds during the period 1986-1989. The model is a descendant of the one by Hurlburt and Thompson [1980] but with extended capability [Hurlburt et al., 1992]. Model heights and currents are available at 3-day intervals and are evaluated in the domain $10^{\circ} \mathrm{N}$ to $30^{\circ} \mathrm{N}$ and $160^{\circ} \mathrm{E}$ to $120^{\circ} \mathrm{W}$. The model time series are high pass filtered in time to eliminate variability at periods greater than $\mathbf{2 0 0}$ days using the same filter applied to the Wake Island sea level data.

\subsection{Propagating Signals From Big Island to Wake Island}

The first question is whether the model sea level data are similar to the Wake Island and Geosat data. A computation of the variance of the model sea level at $19^{\circ} \mathrm{N}$ versus longitude (Figure 12) shows the region from just east of the 


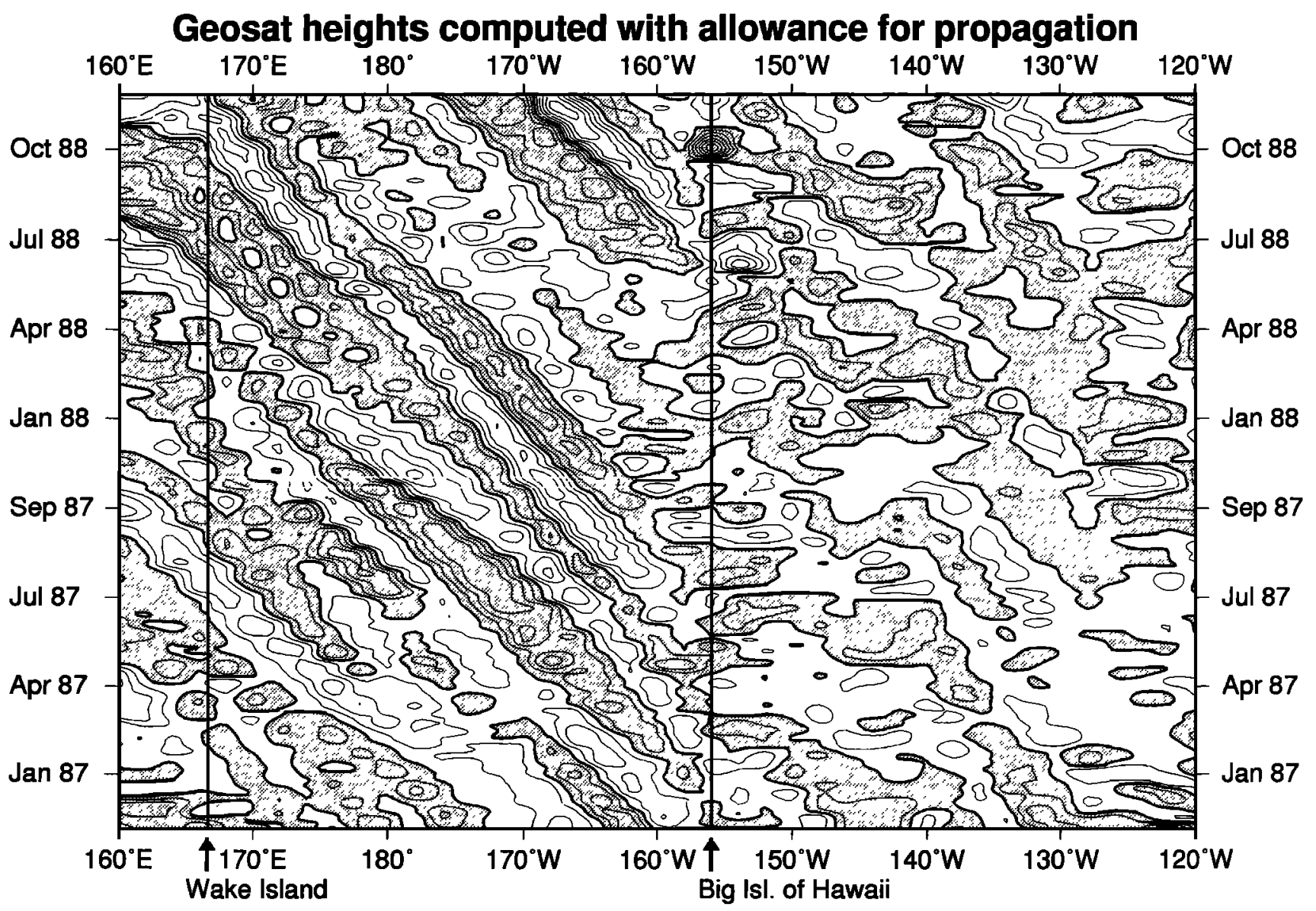

Figure 10. Geosat time series (computed with allowance for propagation) were formed between $160^{\circ} \mathrm{E}$ and $120^{\circ} \mathrm{W}$ and between $10^{\circ}$ and $30^{\circ} \mathrm{N}$. This figure shows a time-longitude cut along $19^{\circ} \mathrm{N}$. This latitude falls close to both Wake Island and the Big Island of Hawaii. The slanting features in the left portion of the plot are propagating westward at about $7 \mathrm{~cm} / \mathrm{s}$. Negative sea surface heights are shaded and the contour interval is $3 \mathrm{~cm}$.

Big Island westward to the dateline to be an area of increased sea level variability at high frequencies. The rms variability near Wake Island, however, is only about $80 \%$ of the observed value. Estimates of the zonal propagation speed via the calculation described in section 3.3 are similar to those obtained from the Geosat data (Figure 13). A simple comparison of the time series at Wake Island, however, does not show agreement between the model heights and the observed sea level data.

A more direct comparison was made by using the model output to form a time-longitude description of the sea surface heights along $19^{\circ} \mathrm{N}$ (Figure 14). This plot is analogous to the description from the Geosat data shown in Figure 10. The model heights reveal propagating signals between the Big Island and Wake that are similar in character, although not in detail, to those derived from the Geosat data. Given this similarity, it is reasonable to examine the high-resolution model heights in more detail near the Big Island to study the features that give rise to the propagating signals. This must be done carefully, however, since the model signals are of longer period and propagate more slowly than the observed waves. The reasons for this are unknown at present.

\subsection{A Case Study of Eddy Generation and Propagation}

The eddies generated near the Big Island were studied extensively by animating the model sea surface height and upper layer current fields. Qualitatively, the eddies observed in the model output can be placed in three categories. First, there are relatively small cyclonic eddies that are formed west of the Big Island and tend to remain in the lee of the island chain. These eddies appear to be similar to those discussed by Patzert [1969]. Second, several degrees south of the Big Island, there are eddies associated with the westward flowing NEC. These eddies are similar to those discussed by Wyrtki [1982]. Although these eddies are numerous and strong, they do not typically affect the sea level at the latitude of Wake and the Big Island. Finally, there are several anticyclonic eddies generated off the south point of the Big Island that are associated with westward current events impinging on the Big Island, as were mentioned in section 3.

It is this third type of eddy that is considered important in the present context. These eddies tend to propagate along $19^{\circ} \mathrm{N}$ and could influence the sea level at Wake Island. One 


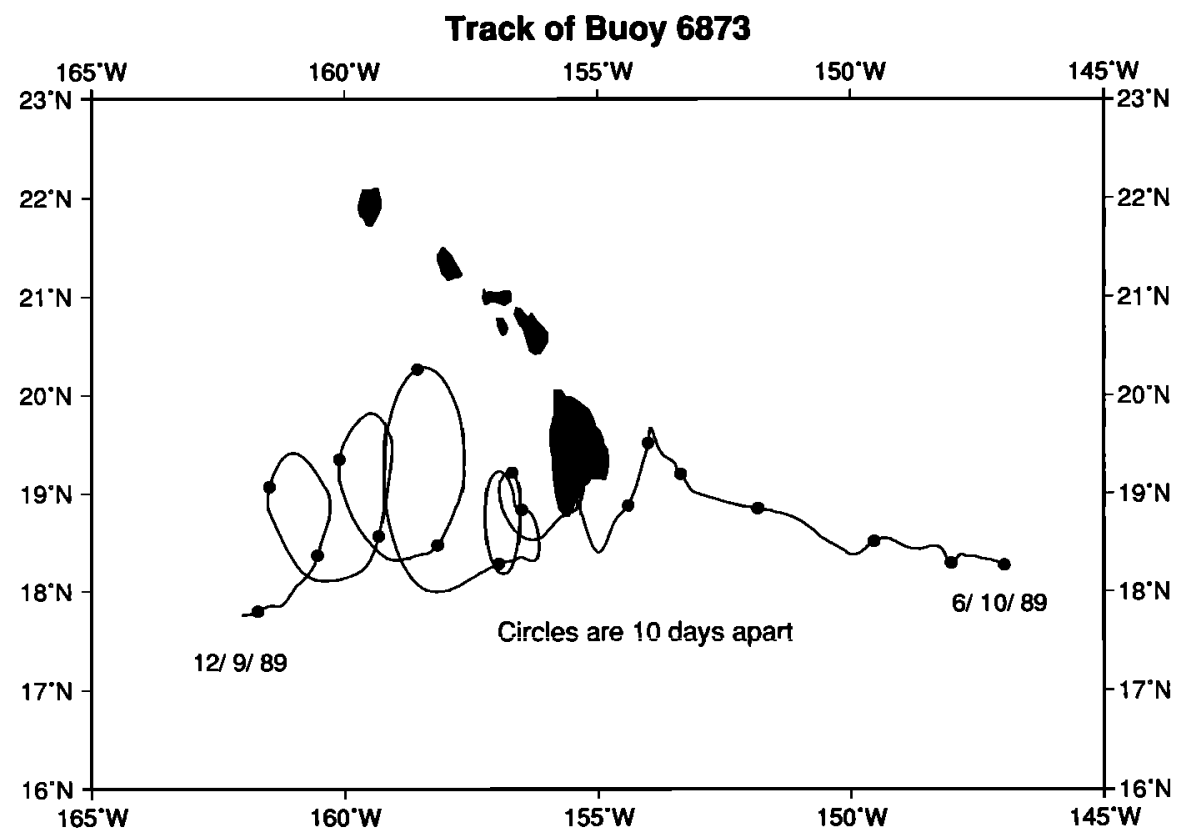

Figure 11. The solid line is produced from 6-hour buoy positions. The solid circles are drawn every 10 days. The islands shown are the main Hawaiian Islands, with the southernmost island being the Big Island of Hawaii. The buoy track is traced from June 10 to December 9, 1989.

case, which occurred near the end of 1986, was isolated to illustrate the generation of this type of eddy (Figure 15). First, westward currents associated with a large anticyclonic feature centered at about $21^{\circ} \mathrm{N}$ reach the Big Island on day 269 of 1986, and an anticyclonic eddy begins to form just west of the south point of the island. By day 330 of 1986 the eddy is a very distinct feature and is centered on $160^{\circ} \mathrm{W}$, and by day 360 the eddy has moved further west and is clearly separated from the island. To this point the eddy has propagated west at an average speed of about $5 \mathrm{~cm} / \mathrm{s}$, but the propagation speed increases to $7 \mathrm{~cm} / \mathrm{s}$ after this time. It is not clear whether this eddy is interacting with the NEC west of the Big Island. It is clear, however, that there is not a preexisting eddy near the Big Island that is simply separated from the topography by the westward current.

An attempt was also made to study any modification of the

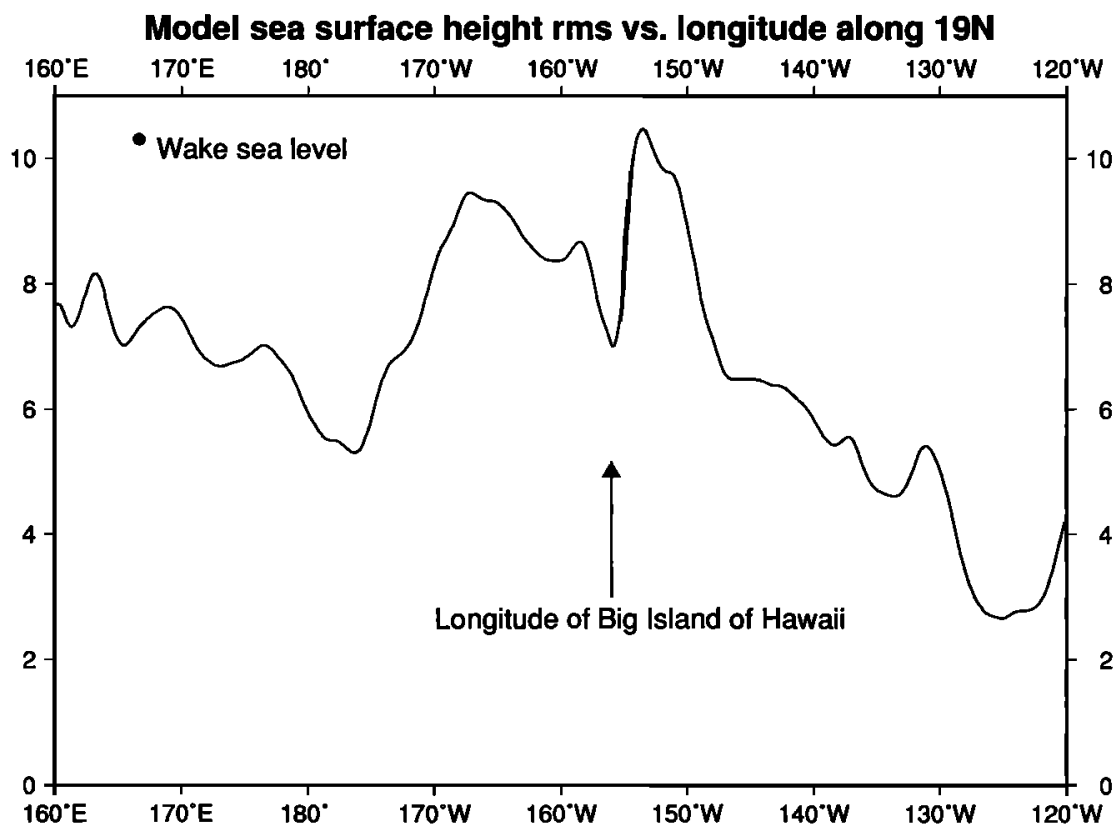

Figure 12. High-passed sea surface heights from the NRL model are used to compute the rms temporal variability along $19^{\circ} \mathrm{N}$. The units are in centimeters. The analogous value for the high-passed Wake sea level data is also shown for comparison. 


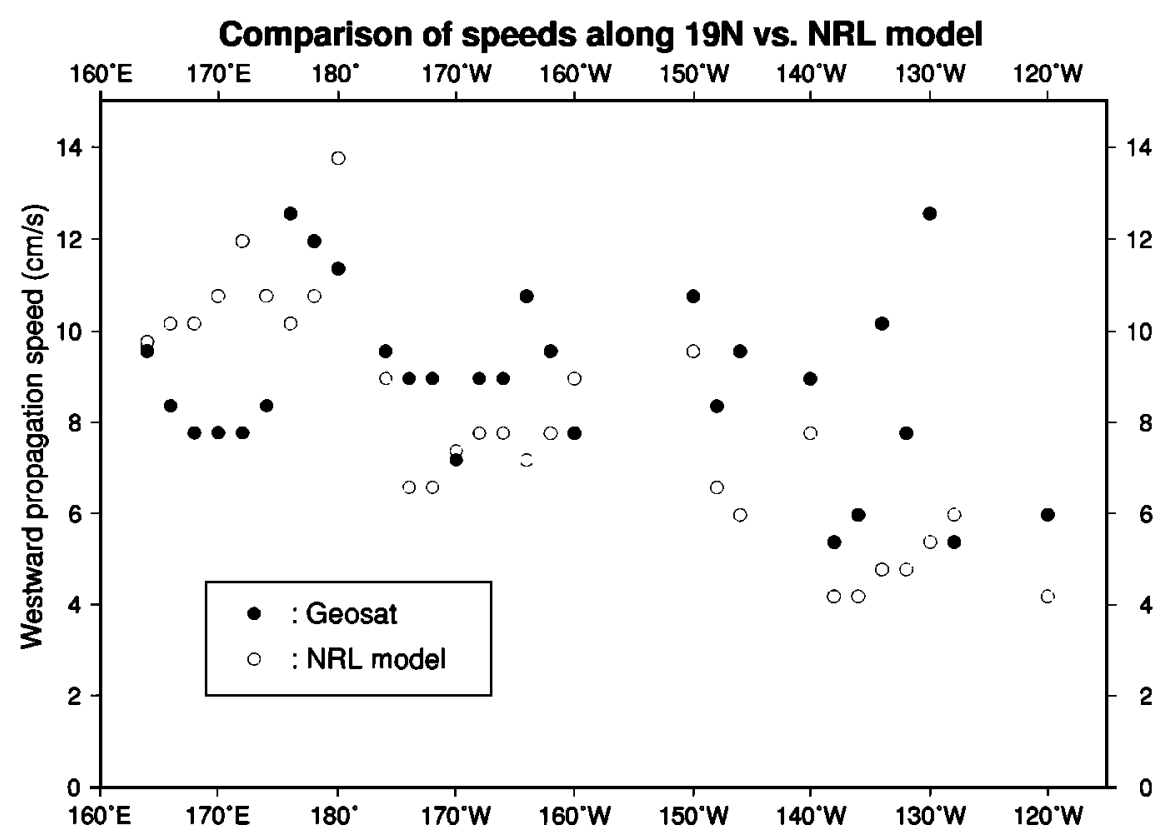

Figure 13. The technique (described in the text) used to estimate propagation speeds for the purpose of combining Geosat grid point time series into higher-resolution time series with allowance for propagation is also used to estimate propagation speeds from the NRL model height values. These values are compared to the Geosat values in this figure. In both cases, propagation speeds are comparable to those expected for Rossby waves. Several outliers have been rejected before making this comparison.

eddy as it moves westward. The same anticyclonic eddy was tracked until early 1988 when it reached the longitude of Wake Island (Figure 16). The desire to track the eddy in this fashion arises from the possibility that such an isolated vortex will decay into a wave-like feature after several months and thus may explain the waves, as opposed to single eddies, observed at Wake Island. Firing and Beardsley [1976] demonstrated this for barotropic eddies, and Flierl [1977] discussed this process for the baroclinic case. Flierl's study (see his Figure 6.5) showed that a baroclinic eddy of order $500-\mathrm{km}$ diameter decayed into a wave-like feature with a wavelength of order $500 \mathrm{~km}$ after approximately 1-2 years. Obviously, these parameters are very similar to those observed in the present case. Unfortunately, the anticyclonic eddy shown in Figure 16 does not behave in such a simple fashion. Although the eddy reaches Wake in early 1988 when the 90-day waves at Wake are observed, the eddy has not decayed into a train of waves. There is, however, some indication in the last several snapshots that the eddy is splitting into a more wave-like feature. For example, at day 91 of 1988 there are a maximum and a minimum separated by about $5^{\circ}$ of longitude, implying a wavelength of order 1000 $\mathrm{km}$. A simpler description, however, would be that the eddy simply decreases in amplitude and fades into the background height field. The fact that the eddy does not appear to decay into a wave train may not be surprising since we already know that the model's sea surface height time series at the location of Wake Island does not agree with the observed sea level time series.

\section{Discussion}

On the basis of the data described in the preceding sections, the most likely explanation for the intermittent 90-day oscillations observed in the Wake Island sea level record is that these signals are Rossby waves associated with eddies generated by westward flow past the Big Island of Hawaii about 1.5 years earlier. The Geosat data clearly support the interpretation of the 90-day oscillations as Rossby waves by documenting not only the appropriate propagation speed but also a wavelength close to that expected from the dispersion curve for Rossby waves. The Geosat data also clearly connect these waves in the western Pacific with a source region at the Big Island of Hawaii. The NRL model output suggests that eddies associated with westward flow past the Big Island are the source of energy, but this portion of the explanation is more speculative.

If it is assumed for the moment that eddies generated by flow past the island provide the correct explanation, then the question naturally arises as to how the eddies are generated. Patzert [1969] briefly considers the possibility that westward flow past the Big Island generates a von Karman vortex street that would explain the eddies observed south of the Big Island. He rejects this hypothesis on the basis that the currents in the region of the Big Island are not strong and steady enough to generate significant eddies. This hypothesis is worth reconsidering, however. According to the von Karman vortex street theory [Lamb, 1945], a cylinder (of diameter $d$ ) in a steady flow (of speed $U$ ) generates a series of vortices at both the top and bottom of the cylinder. These vortices rotate opposite to one another. The vortices at the bottom, which would correspond to the south point of the Big Island, are anticyclonic for westward flow and are separated by a distance of $3.5 \mathrm{~d}$. Taking the diameter of the Big Island to be $150-200 \mathrm{~km}$ yields a separation distance for the anticyclonic vortices of $525-700 \mathrm{~km}$, which is similar to the wavelength of the waves observed far downstream from 


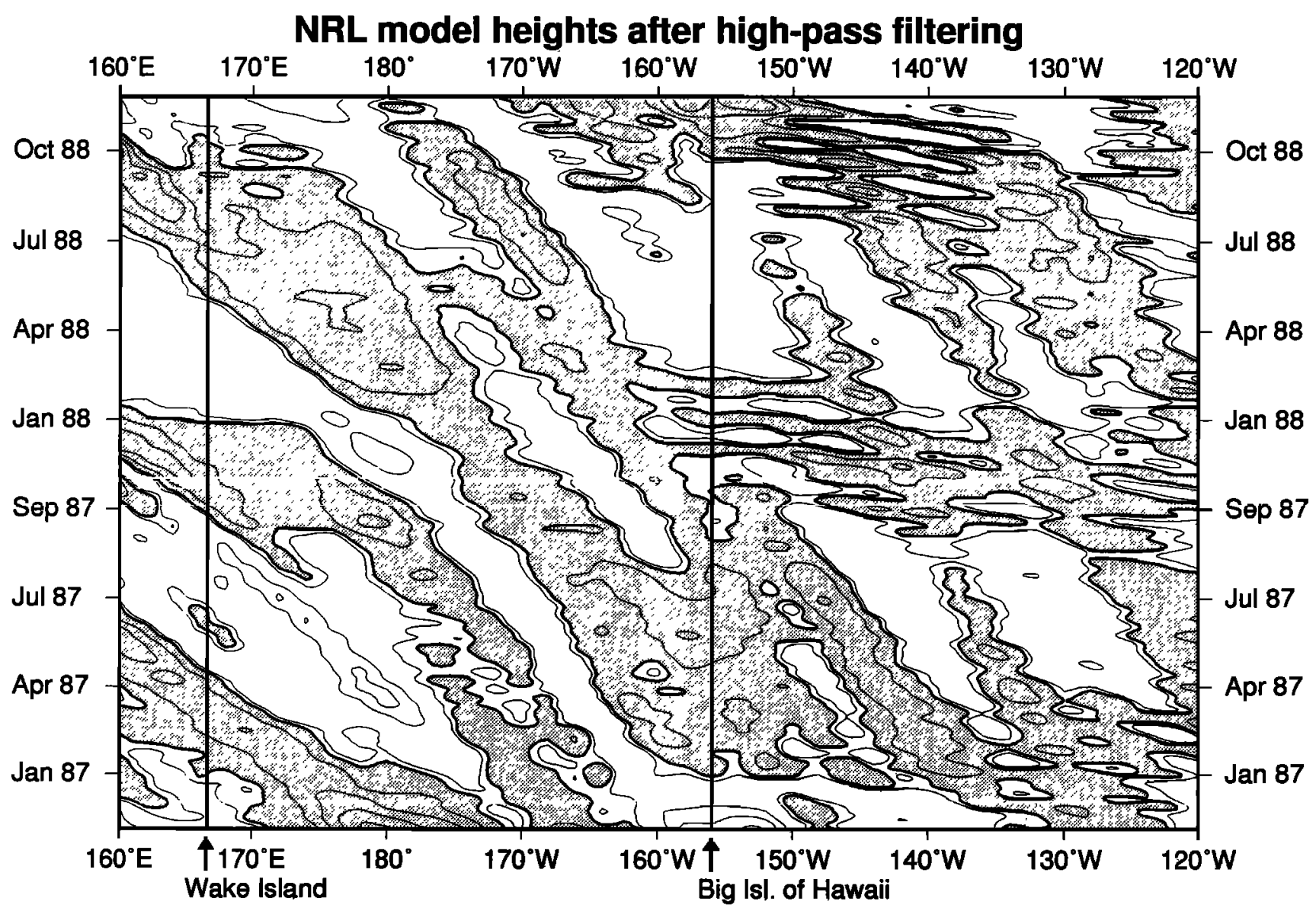

Figure 14. This plot uses the high-passed NRL sea surface heights to make a plot that is completely analogous to Figure 10, which uses the Geosat heights. Negative heights are shaded and the contour interval is $3 \mathrm{~cm}$. The slanting features in the western portion of the plot represent westward propagating signals.

the Big Island. The period associated with Rossby waves at this wavelength is $75-100$ days. A period can also be derived from the separation period of the vortices, which is $10 \mathrm{~d} / \mathrm{U}$. A period of 90 days would imply a current of $15-20 \mathrm{~cm} / \mathrm{s}$. This current speed is reasonable during flow events such as that described from the NRL model in the previous section. These current speeds are not typical near the Big Island, however, because the northern edge of the NEC usually lies several degrees south of Hawaii. It is also interesting to note that Barkley [1972] described a set of observations near Johnston Atoll that he interpreted as consistent with a von Karman vortex street generated by a strong flow past the island.

Although these scales suggest various resonance possibilities, there are major problems with this scenario as well. One serious objection is that an isolated cylinder simply does not fit the geometry of the Hawaiian Island chain very well. The channel north of the Big Island is not large enough to effectively isolate the Big Island from the chain; this can easily be seen in the sequence of plots shown in Figure 15. A better model for the Big Island would be a wedge protruding into a flow or a flow accelerating past such a wedge. Such a flow and wedge geometry is known to generate starting and stopping vortices [e.g., Pullin and Perry, 1980], but it is unclear whether the scales of the eddies thus generated would agree with the anticyclonic eddies observed south of the Big Island.

A more serious problem, however, is that the von Karman theory does not include rotation or stratification and is thus clearly suspect. On the other hand, more general laboratory experiments indicate that eddy generation by flows past obstacles such as the Big Island is a robust process. For example, Klinger [1994] considered baroclinic flow in a rotating fluid along a wall that had a sharp corner. He concluded that the generation of eddies at the corner is similar to the nonrotating, unstratified case but that rotation tends to suppress the eddy generation while baroclinicity tends to increase it. Another interesting laboratory study is described by Boyer and Tao [1987]. In this experiment a rotating, stratified fluid moved along a wall past a wedgeshaped obstacle with sloping sides. This geometry was intended to model flow past a cape on a coastline. These authors find that for parameters similar to the real ocean, eddies are formed past the wedge when the fluid is stratified. They also note that increasing the flow rate or the stratification causes the eddy to separate and propagate downstream, at which point it is replaced by a new eddy. These studies are cited only to show that eddy generation at the Big Island by a westward flow event is a viable possibility.

Another area of uncertainty concerns the fate of the eddies 


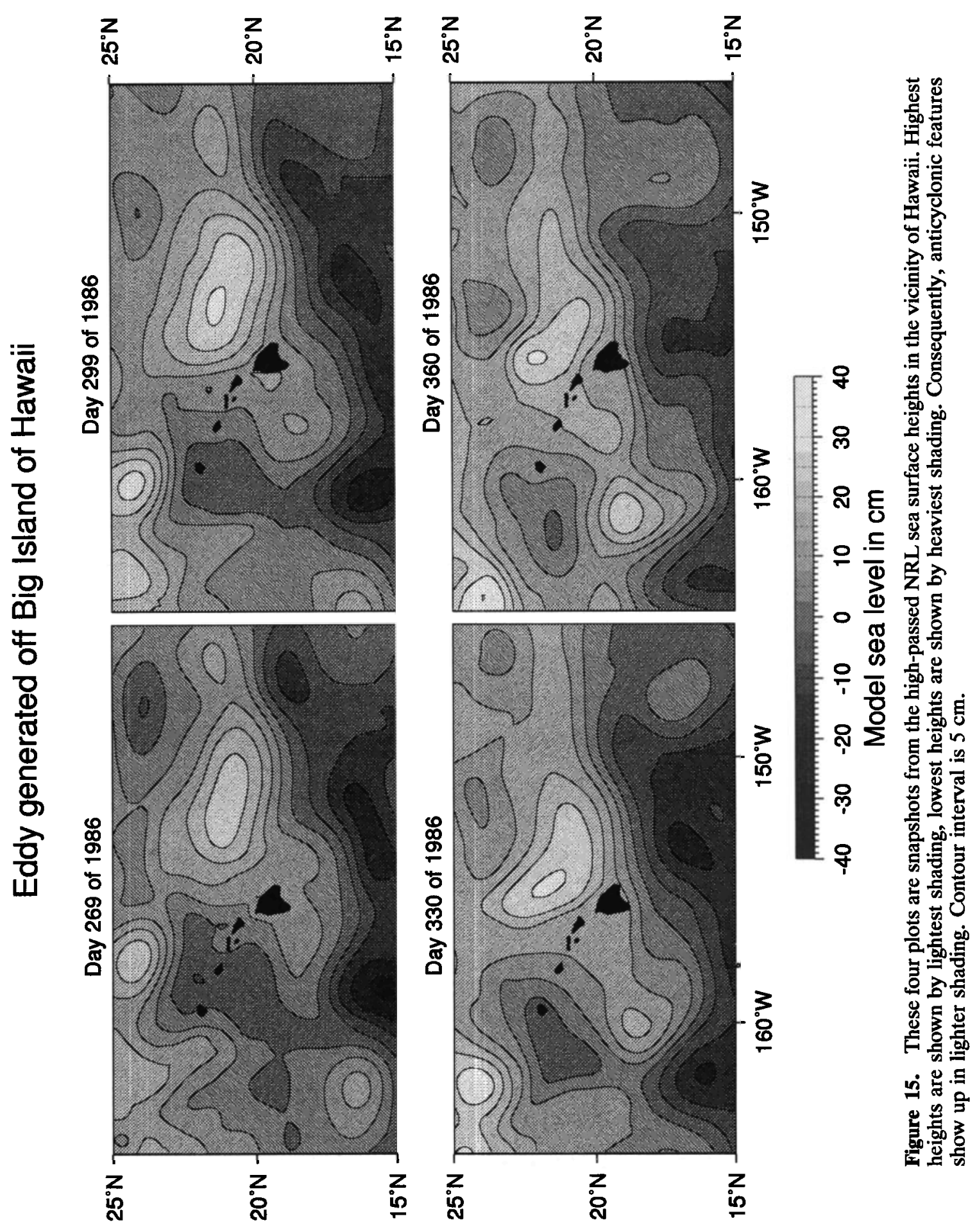




\section{Eddy evolution during westward propagation}

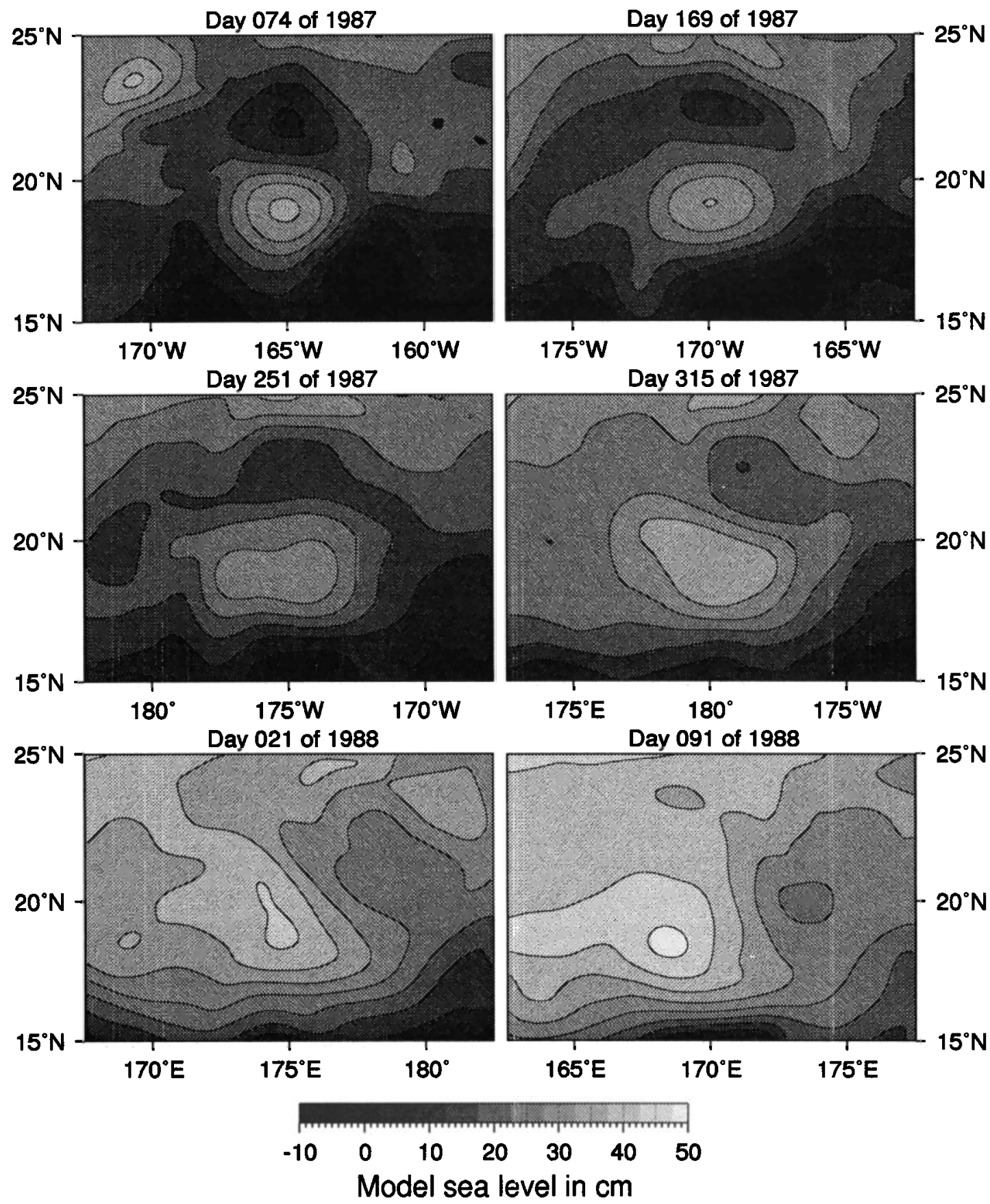

Figure 16. This figure is similar to Figure 15 except that the snapshots are through a window that is propagating westward at approximately $7 \mathrm{~cm} / \mathrm{s}$. The anticyclonic feature being tracked is the same one that is formed in the sequence shown in Figure 15. The contour interval is $5 \mathrm{~cm}$.

as they propagate westward toward Wake Island. It is clear from the Geosat and Wake sea level data that the signals are in the form of Rossby waves, at least west of the dateline. As noted earlier, Flierl [1977] has described the decay of eddies into waves, but the data are inadequate to document that process in this case. It is possible that future, more accurate, altimetry missions such as the presently operational TOPEX/POSEIDON satellite might eventually shed more light on this matter after another set of the 90-day oscillations are observed.

Of course, the eddies at the Big Island were not the only explanation considered in the course of this work. One other possibility was mentioned earlier, namely that the waves are generated in the eastern Pacific near $10^{\circ} \mathrm{N}$ where the calculation of 90-day sinusoids revealed energetic signals (Figure 7). These signals may be due to Rossby wave radiation from 


\section{Geosat heights at $170 \mathrm{E}$}

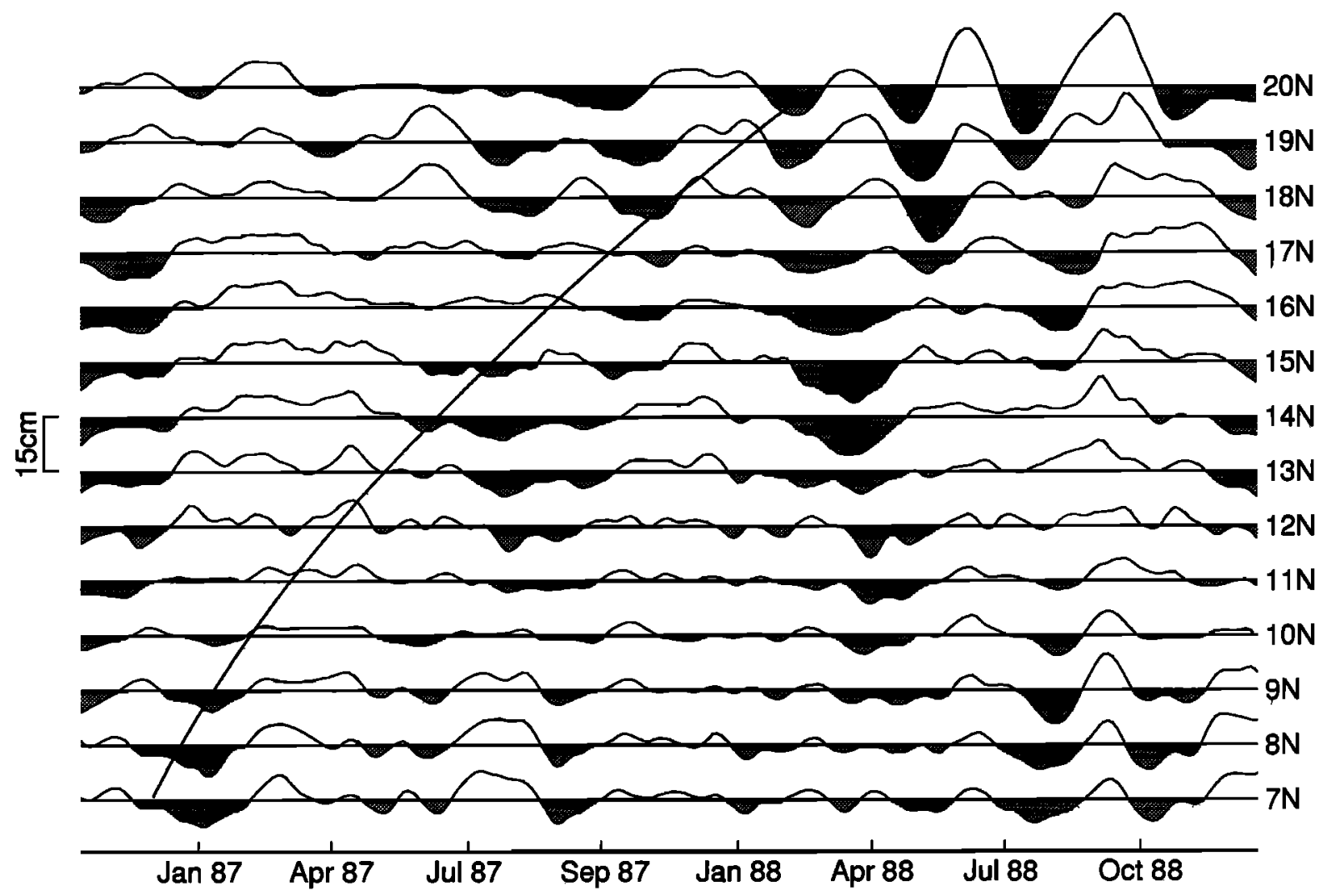

Figure 17. The Geosat heights that were computed with allowance for propagation are plotted at $1^{\circ}$ meridional spacing along $170^{\circ} \mathrm{E}$. Negative heights are shaded and the individual curves are offset by $15 \mathrm{~cm}$ for visibility. The solid curve follows the arrival time expected for a signal propagating from east of $170^{\circ} \mathrm{E}$ at the Rossby wave speed appropriate for each latitude. The meridional variation of the Rossby wave speed used to estimate the arrival time is the same as for the solid curve shown in Figure 8 . The latiţudes are given along the right edge of the plot.

Kelvin wave events originating in the tropical Pacific and propagating along the coast of the Americas [Enfield, 1987]. Although these waves appear to originate well south of the latitude of Wake Island, it is possible that refraction would explain their appearance at Wake (recall that the turning latitude at the 90 -day frequency is about $20^{\circ}$ ). As stated in the earlier section, however, it is impossible to detect the waves between the eastern Pacific and Hawaii or Wake Island, and therefore this hypothesis was rejected.

Another possibility arises from the fact that the equatorial Kelvin wave pulses associated with the ENSO events are typically of a size that, when coupled to their propagation speed of $2.5-3 \mathrm{~m} / \mathrm{s}$, gives rise to a timescale of order 90 days. In fact, such 90-day events are relatively easy to detect in western Pacific stations near the equator during the ENSO events. These Kelvin pulse events can be forced by patches of westerly winds [McCreary and Lukas, 1986]. It could be speculated that this 90 -day event on the equator could give rise to Rossby waves off the equator that would propagate westward. This possibility was examined by plotting the time series computed in section 3.3 at $170^{\circ} \mathrm{E}$ as a function of latitude and time (Figure 17). The top curve at $20^{\circ} \mathrm{N}$ corresponds to Wake Island. The event in January 1987 in the bottom curve at $7^{\circ} \mathrm{N}$ corresponds to the Kelvin wave event during the ENSO event. The line progressing from top to bottom and left to right through the figure shows the lag expected for signals propagating at the speed computed via the calculation described in section 3.3. If the signals at Wake Island were associated with the equatorial event, then it should be possible to track the event along the line. This is not possible, however, and thus this hypothesis was also rejected.

Another possibility that was considered is much simpler. It is possible that the Rossby waves observed at Wake Island are generated by Ekman pumping by the wind stress in the open ocean somewhere to the east of Wake Island. Meyers [1979] has shown, for example, that this process can explain a significant amount of the sea level variability in the western Pacific at the annual period. This hypothesis does not explain, however, why it is possible to easily track the signals all the way from Wake Island to the Big Island of Hawaii. Also, a simple scaling argument makes this explanation seem unlikely. Basically, the amplitude of the wind stress curl variation required to generate a given upper layer anomaly scales as the frequency of the variation. While this mechanism works well at annual periods, a period of 90 days requires a much larger, and unreasonable, wind stress curl signal. 
In summary, evidence has been presented that explains the 90-day sea level oscillations observed in the Wake Island sea level as the expression of Rossby waves with an energy source near the Big Island of Hawaii. It has not been possible, however, to unambiguously link the Rossby waves with the decay of eddies generated at the Big Island of Hawaii or to demonstrate that the eddies are associated with westward flow impinging on the island. This is considered the leading hypothesis, however, particularly given the lack of success of several other possible explanations. Future events that are observed from modern altimeters may lead to further progress, and more detailed descriptions should result from future numerical modeling experiments. I will close with the idea that, if the Rossby waves at Wake Island can be clearly linked to eddies generated at the Big Island, then these data can serve as a sensitive test of a model's ability to properly account for the decay and modification of eddies as they propagate away from their source region.

Acknowledgments. This work was supported by NOAA through the Joint Institute for Marine and Atmospheric Research Cooperative Agreement NA37RJ0199 and by NASA through the Jet Propulsion Laboratory as part of the TOPEX Altimeter Research in Ocean Circulation Mission. The views expressed herein are those of the author and do not necessarily reflect the views of NOAA or any of its subagencies. Computing support was provided by Shikiko Nakahara and Bernard Kilonsky. NRL model fields were supplied courtesy of Harley Hurlburt. I am pleased to acknowledge many stimulating conversations with Eric Firing and Dennis Moore, as well as with Klaus Wyrtki, who pointed out the Wake Island sea level oscillations to me several years ago. The paper was also significantly improved by suggestions from two anonymous reviewers. This is contribution 3767 of the School of Ocean and Earth Science and Technology, University of Hawaii; JIMAR contribution 94-281.

\section{References}

Barkley, R., Johnston Atoll's wake, J. Mar. Res., 30, 201-216, 1972. Bloomfield, P., Fourier Analysis of Time Series: An Introduction, John Wiley, New York, 1976.

Boyer, D., and L. Tao, On the motion of linearly stratified rotating fluids past capes, J. Fluid Mech., 180, 429-440, 1987.

Chelton, D., and M. Schlax, Spectral characteristics of timedependent orbit errors in altimeter height measurements, $J$. Geophys. Res., 98, 12,579-12,600, 1993.
Enfield, D., The intraseasonal oscillation in the eastern Pacific sea level: How is it forced?, J. Phys. Oceanogr., 17, 1860-1876, 1987.

Firing, E., and R. Beardsley, The behavior of a barotropic eddy on a $\beta$-plane, J. Phys. Oceanogr., 6, 57-65, 1976.

Flierl, G., The application of linear quasigeostrophic dynamics to Gulf Stream Rings, J. Phys. Oceanogr., 7, 365-379, 1977.

Gill, A., Atmosphere-Ocean Dynamics, Academic, San Diego, Calif., 1982.

Haines, B., G. Born, G. Rosborough, J. Marsh, and R. Williamson, Precise orbit computation for the Geosat Exact Repeat Mission, J. Geophys. Res., 95, 2871-2886, 1990.

Hurlburt, H., and J. Thompson Jr., A numerical study of Loop Current intrusions and eddy shedding, J. Phys. Oceanogr., 10, 1611-1651, 1980.

Hurlburt, H., A. Wallcraft, Z. Sirkes, and E. Metzger, Modeling of the global and Pacific oceans: On the path to eddy-resolving ocean prediction, Oceanography, 5, 9-18, 1992.

Klinger, B., Baroclinic eddy generation at a sharp corner in a rotating system, J. Geophys. Res., 99, 12,515-12,531, 1994.

Lamb, H., Hydrodynamics, 6th ed., Dover, Mineola, N. Y., 1945.

McCreary, J., and R. Lukas, The response of the equatorial ocean to a moving wind field, J. Geophys. Res., 91, 11,691-11,705, 1986.

Meyers, G., On the annual Rossby wave in the tropical North Pacific Ocean, J. Phys. Oceanogr., 9, 663-674, 1979.

Mitchum, G., and B. Kilonsky, Observations of tropical sea level variability from altimeters, in Oceanographic Application of Remote Sensing, edited by M. Ideda and F. Dobson, CRC Press, Boca Raton, Fla., in press, 1994.

Mitchum, G., and R. Lukas, The latitude-frequency structure of Pacific sea level variance, J. Phys. Oceanogr., 17, 2362-2365, 1987.

Patzert, W., Eddies in Hawaiian waters, Tech. Rep. HIG-69-8, 51 pp., Hawaii Inst. of Geophys., Univ. of Hawaii, Honolulu, 1969.

Pullin, D., and A. Perry, Some flow visualization experiments on the starting vortex, J. Fluid Mech., 97, 239-255, 1980.

Seckel, G., Seasonal variability and parameterization of the Pacific North Equatorial Current, Deep Sea Res., 22, 379-401, 1975.

Tai, C.-K., Geosat crossover analysis in the tropical Pacific, 1, Constrained sinusoidal crossover adjustment, J. Geophys. Res., $93,10,621-10,629,1988$.

van Woert, M., and J. Price, Geosat and advanced very high resolution radiometer observations of oceanic planetary waves adjacent to the Hawaiian Islands, J. Geophys. Res., 98, 14,619$14,632,1993$.

Wyrtki, K., Eddies in the Pacific North Equatorial Current, J. Phys. Oceanogr., 12, 746-749, 1982.

G. T. Mitchum, UH Sea Level Center, University of Hawaii, 1000 Pope Road, Honolulu, HI 96822.

(Received September 13, 1993; revised October 24, 1994; accepted November 8, 1994.) 